\title{
Performance of Children and Adolescents from a School of the City of Sogamoso on a Decision-Making Test
}

\author{
Patricia Bernal*, Johanna Montaña, Rocio Acosta, Yonathan Rojas \\ Universidad de San Buenaventura, Bogotá, Colombia \\ Email: "arlethpatriciab@gmail.com
}

Received 13 November 2015; accepted 27 December 2015; published 30 December 2015

Copyright @ 2015 by authors and Scientific Research Publishing Inc.

This work is licensed under the Creative Commons Attribution International License (CC BY). http://creativecommons.org/licenses/by/4.0/

(c) (i) Open Access

\begin{abstract}
The aim of this study was to describe the performance on a decision-making task of children and adolescents (aged 7 - 17 years) from a school in the city of Sogamoso. This non-experimental descriptive, cross-sectional study was conducted by means of a non probability sampling of type cases. The sample consisted of 325 subjects, to whom the Hungry Donkey Task in its version adapted for Colombia was applied. Through descriptive statistics, the test performance trend was established, finding that participants aged 7 to 11 years had better performance than adolescents 12 to 14 years old, which partially supports the hypothesis of decision-making development in J shape. Subjects aged 15 to 17 years had the most disadvantageous performance, which may indicate immaturity and slow development of prefrontal areas and the influence of the trend towards risk-taking, characteristic of this age range.
\end{abstract}

\section{Keywords}

Decision-Making, Children and Adolescents, Somatic Marker, Hungry Donkey Task

\section{Introduction}

Decision-making is defined as the ability to select the course of action from a set of behavioral alternatives oriented to favorable or unfavorable options involving cognitive aspects, reward and punishment contingencies and emotional signals associated with each of the possible responses [1].

Decision-making requires the processing of emotions, according to the somatic marker model (MS) proposed by Damasio [2], where emotions and cognition are integrated to make decisions based on the future potential

\footnotetext{
${ }^{*}$ Corresponding author.
}

How to cite this paper: Bernal, P., Montaña, J., Acosta, R. and Rojas, Y. (2015) Performance of Children and Adolescents from a School of the City of Sogamoso on a Decision-Making Test. Open Journal of Pediatrics, 5, 339-347. 
consequences of behavior, rather than on the immediate ones [3]-[9].

The MS model involves a processing system for primary emotions that depend on the limbic system (innate and prearranged reactions to an environmental stimulus) and another one for secondary emotions that require prefrontal and somato-sensory cortices [10]-[12]. Primary emotions are innate, while secondary ones are developed throughout life, although these have a major development peak during adolescence [3].

During adolescence, new synapses are established in the prefrontal area [13] and myelination progresses in the frontal cortex and in the paths that link it to other brain areas such as some limbic structures (amygdala, hippocampus and caudate nucleus), with an impact on the development of decision-making capacity, by improving the inhibitory control, organizing emotional inputs and determining the behavioral response [13]-[16] However, this is a process which is accompanied by periods of limbic over-activation generating imbalance between the adolescent's emotional experience and their ability to regulate their motivation and arousal [17]. Should it persist, will be related to increased risk behaviors [18], but should it mature, will lead to a reduction in the mesolimbic excitability and strengthening of cortical control with adoption of more adaptive behaviors [12].

The first studies carried out to assess decision-making in children and adolescents used two adapted versions of the Iowa Gambling Task (IGT): The Children's Gambling Task, adapted by Kerr and Zelazo in 2004 [19], and later The Hungry Donkey Task (HDT) adapted by Crone and Van der Molen in 2004 [20]. Regarding the HDT, it has been found that children between 7 - 12 years old, as well as patients with damage to the ventromedial prefrontal cortex (VMPFC), choose options that result in higher immediate profits despite large future losses, because they base their performance on the number of items they win, no matter how many items they lose [21] [22]. Additionally, it has been found that with age, the strategy changes towards finding a more proportional gain [23], and children from 7 to12 years old, who seem to have a myopia about the future, increase their sensitivity to future consequences when the potential punishment is high [20].

It has further been found that the development of decision-making in subjects from 7 to 17 years old shows a trajectory in the form of a $\mathrm{J}$, where the youngest showed a less unfavorable performance than early adolescents, who from the age of 14 begin to present a more advantageous performance, as prefrontal cortex development progresses, being better able to inhibit their initial impulsive responses [24]. According to these authors, the poor performance of early adolescents is not indicative of pathology, but of immaturity of the frontal areas, which will continue to mature throughout adolescence until achieving better control of their executive functions.

The aim of the study is to describe the performance of Colombian children and adolescents on the Hungry Donkey Task, according to three age ranges (7 - 11, 12 - 14 and 15 - 17 years), at a school in the city Sogamoso. This in order to understand the mechanisms that guide adequate or inadequate decision-making in different age groups, with particular emphasis on brain maturation as a fundamental aspect in the final configuration of an individual that fits the demands of the environment, making decisions based on future consequences.

\section{Method}

This is a non-experimental descriptive cross-sectional study, which it was made during 2014. A non-probability sampling was done for convenience, and included all children and adolescents of both genders aged 7 - 17 years, from a school of the medium stratum of city of Sogamoso, Colombia with semi-customized education, without learning or behavioral disorders and without neurological or psychiatric impairments. Through a non-probability sampling of type cases, participants were chosen with a similar profile, upon reviewing their medical history (reported by parents).

Exclusion criteria: Presence of history of behavioral or learning disorders, brain damage or neurological or psychiatric impairments whose implications persist today.

The informed consent was completed by 358 children (129 males and 196 females), with a homogeneous level of participation from grades $3^{\circ}$ to $11^{\circ}$, except for grade $5^{\circ}$ which had a better participation (4.3\%), since not all students were at school that day. 25 data were eliminated for not having finished the task and 7 exclusions were made in accordance with established criteria. Finally, the sample consisted of 325 children and adolescents (see Table 1).

\subsection{Instruments}

“The Hungry Donkey Task” by Crone and Van der Molen [23] is a Colombian adaptation of the test. The task is presented through a software that displays 4 doors and the goal is to collect as many apples as possible. The four 
options (P1, P2, P3 and P4) systematically differ in the amount of gains, losses and frequency thereof. Participants must choose one of the four gates throughout 100 trials. The sum of gains doors 1 and 2 corresponds to 400 and the total losses of 500 blocks; while the doors 3 and 4, the gain is 200 apples and 100 apples losses. In the Table 2 the description of income probabilities of each door is exposed.

Additional, we used a Personal Data Questionnaire and Medical History, which included personal information, prenatal, perinatal and postnatal history, developmental background, treatments undertaken, diagnoses received and family history.

\subsection{Procedure}

Parents were asked to give their informed consent and complete the Personal Data Questionnaire and Medical History. The Hungry Donkey Task was applied to children whose parents authorized their participation and did not meet any exclusion criteria.

All the principles governing scientific research in the field of psychology regarding informed consent, use of data and instruments with theoretical, practical and research support, were fulfilled (Chapter VII Articles 50, 52 and 55; Chapter VI Article 48 - Law 1090 of 2006: Deontological and Bioethical Code of the Psychologist in Colombia). Also, children and adolescents were asked to give their assent to participate (Article 37 of Act 1098 of 2006 - Code for Children and Adolescents of the Republic of Colombia).

\section{Results}

Statistical analysis was performed from SPSS-21 and measures of central tendency and dispersion measures of

Table 1. Frequencies of the sample by age and grade of education.

\begin{tabular}{cccccc}
\hline Age & Frequency & $\%$ & Grade & Frequency & \% \\
\hline 7 & 2 & 0.6 & 3 & 38 & 11.7 \\
8 & 39 & 12.0 & 4 & 14 & 9.8 \\
9 & 28 & 8.6 & 5 & 53 & 4.3 \\
10 & 15 & 4.6 & 6 & 44 & 16.3 \\
11 & 56 & 17.2 & 7 & 41 & 13.5 \\
12 & 40 & 12.3 & 8 & 37 & 12.6 \\
13 & 38 & 11.7 & 9 & 35 & 10.8 \\
14 & 38 & 11.7 & 10 & 31 & 9.5 \\
15 & 39 & 12.0 & 11 & & \\
16 & 29 & 8.9 & & & \\
17 & 1 & 0.3 & & & \\
\hline
\end{tabular}

Table 2. Characteristics of the gates.

\begin{tabular}{ccccc} 
Gate & Programming & Gain & Lost & Interpretation \\
\hline \multirow{3}{*}{ P1 } & 50 times & 4 & 0 & \\
& 10 times & 4 & 8 & High magnitude of gain, high frequency and magnitude of loss \\
& 30 times & 4 & 10 & \\
\hline \multirow{2}{*}{ P2 } & 10 times & 4 & 12 & \\
& 90 times & 4 & 0 & Low loss frequency, high magnitude of loss and gain \\
& 10 times & 4 & 50 & \\
P3 & 50 times & 2 & 0 & \\
& 10 times & 2 & 1 & Loss high frequency and low magnitude of loss and gain \\
& 30 times & 2 & 2 & \\
\hline \multirow{2}{*}{ P4 } & 10 times & 2 & 3 & \\
& 90 times & 2 & 0 & Lower loss frequency and low magnitude of loss and gain \\
\hline
\end{tabular}


all test scores sheds were established. Data were grouped according to three age ranges (7 - 11, 12 - 14 and 15 17 years old).

The following are the results of the study describing the overall performance, the characteristics of the learning process throughout the test, the preference for reward or punishment options, and the reaction time for choosing advantageous and disadvantageous alternatives.

\subsection{Overall Performance}

To calculate the overall performance, the formula $(\mathrm{P} 3+\mathrm{P} 4)-(\mathrm{P} 1+\mathrm{P} 2)$ was used, corresponding to the sum of the number of times advantageous gates are chosen (P3 and $\mathrm{P} 4)$ minus the sum of the number of times disadvantageous gates are selected (P1 and P2) in a total of 100 trials. The calculation produces a positive or negative number (above or below zero). For this test it is assumed that a positive result indicates the choice of more advantageous options (P3 and P4), compared to the disadvantageous ones (P1 and P2).

Table 3 shows that the three groups had an average performance below zero, and that the youngest age group obtained the least disadvantageous performance. Although all three groups had an average yield below zero, it is noteworthy that it was the younger age group who had the least disadvantageous performance; however, it should be noted that the variability of the results in all age groups, proved to be extended as shown by the dispersion indices.

Regarding the overall performance trend, Figure 1 shows that in the group of 7 to 11 years old, the frequency of data in relation to the mean was relatively homogeneous, whereas for subjects aged 12 to 14 years, it shows a higher distribution of the data to the right of the mean, that is, towards a more positive performance. Regarding the latter group (aged 15 to 17 years), a greater data distribution was found towards a negative result, that is, to the left of the mean.

\subsection{Learning Process}

To analyze the learning process achieved by the subjects during the course of the task, the average of the partial performance on the test was calculated using the same formula mentioned for overall performance, but this time

Table 3. Overall performance by age group.

\begin{tabular}{cccccc}
\hline Age Group & N & Mean & SD & Mínimum & Maximum \\
\hline $7-11$ & 140 & -2.9 & 21.1 & -66 & 62 \\
$12-14$ & 116 & -6.2 & 23.5 & -72 & 48 \\
$15-17$ & 69 & -8.3 & 21.2 & -74 & 40 \\
\hline
\end{tabular}

SD: Standard Deviation.
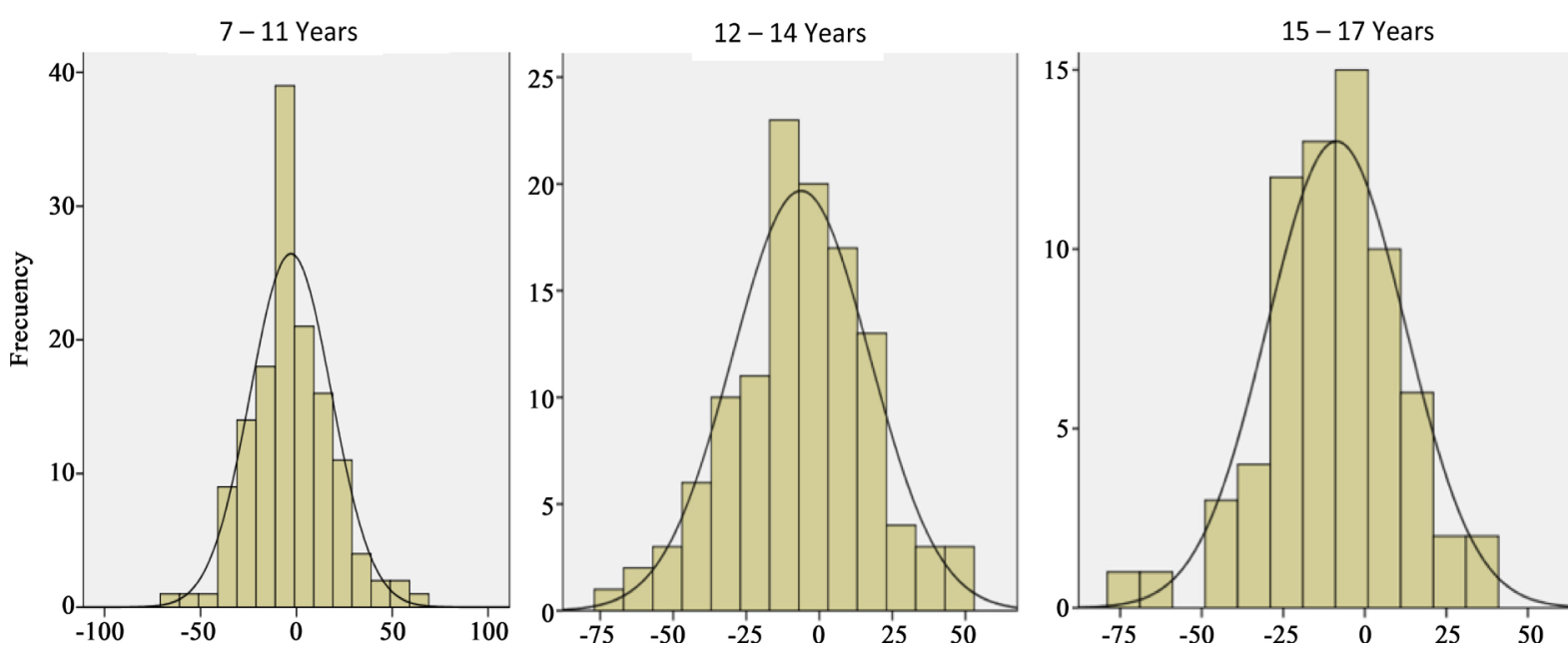

Figure 1. Overall performance trend by age group. 
every 20 trials. Figure 2 shows the average score obtained by each group on partial performances (R1 to R5). According to the observed, it can be deduced that there were not random performances, but that the three groups generated a learning process through the trials, resulting in an upward curve. It should be noted that the first group was the one that presented the most positive performance at the end of the test (mean $=1.16$ ), followed by the group aged 12 to 14 years (mean $=1.1)$. In the case of older individuals (15 - 17 years), the averages of partial performances, although showing an upward trend, they presented a decline around the middle of the test and later regained control toward less disadvantageous choices.

\subsection{Preference for Reward or Punishment Options}

In general terms, children showed a greater preference for P2, which between the two unfavorable options, is the one that provides less frequent punishment. Among the advantageous options (P3 and P4), a slightly higher preference for the last gate was evidenced, which of the four options, is the one presenting the lowest frequency and magnitude of loss (see Figure 3).

\subsection{Response Time}

Children generally had very fast execution times, although there was a more impulsive trend in those who had a negative performance (see Table 4).

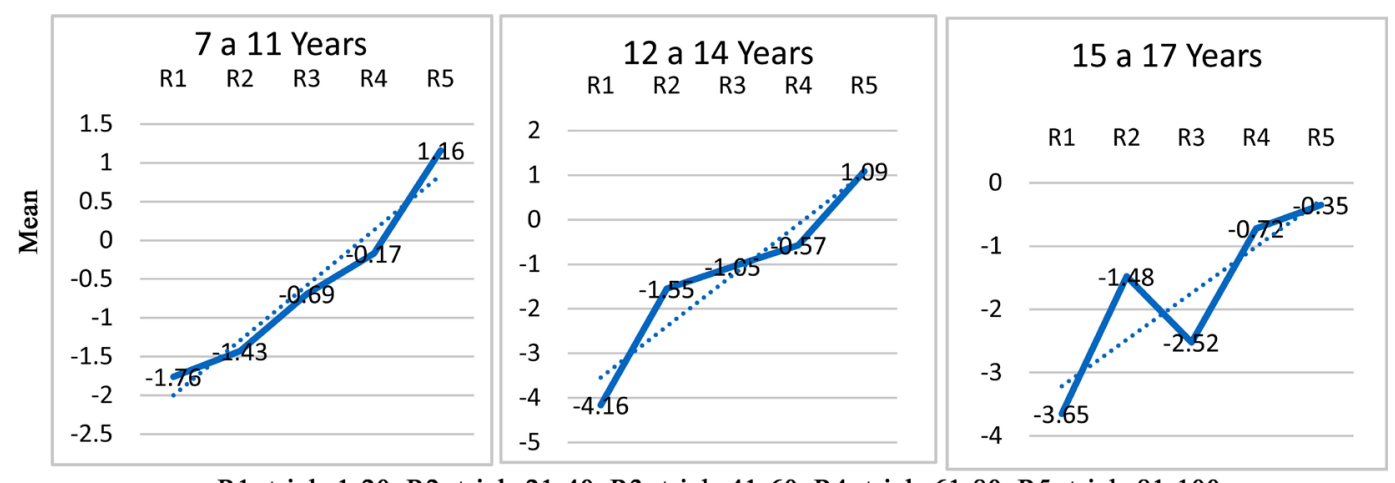

R1: trials 1-20, R2: trials 21-40, R3: trials 41-60, R4: trials 61-80, R5: trials 81-100

Figure 2. Learning curves by age group.

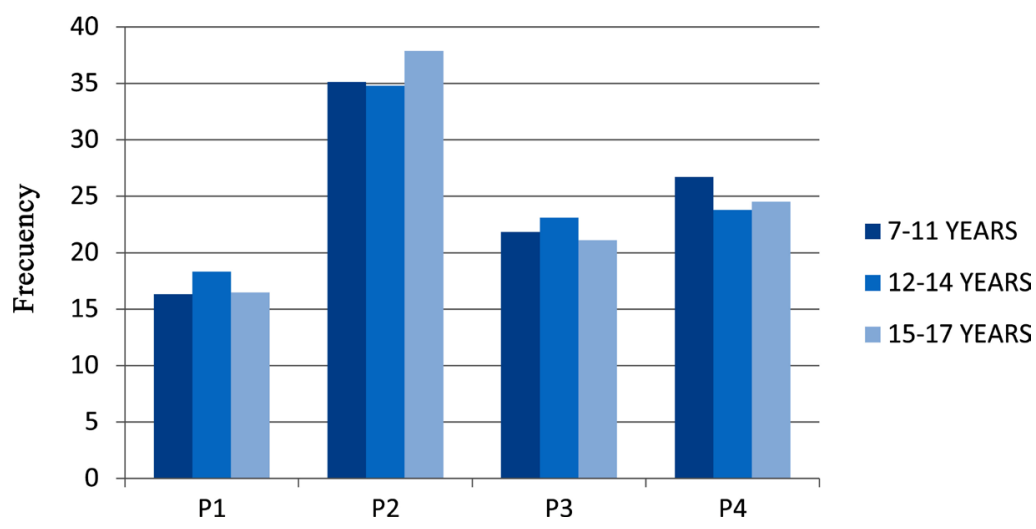

Figure 3. Response options to gate in each age group.

Table 4. Response time as performance in seconds.

\begin{tabular}{cccccc}
\hline Performance & N & Mean & SD & Mínimum & Maximum \\
\hline Positive & 139 & 1.3 & 0.72 & -0.07 & 5.09 \\
Negative & 186 & 1.2 & 0.74 & -0.58 & 4.37 \\
\hline
\end{tabular}

SD: Standard Deviation. 
As for the total execution time on the test, there was no evidence of relevant differences between the time spent by subjects with a positive performance and that of participants who had a negative one (2.27 and 2.23 minutes respectively).

\section{Discussion}

The interpretation of results was carried out on the basis of the somatic marker theory, which argues that the consequences of recent choices influence future decisions. As for overall performance, the theory has reported a linear increase from childhood to adolescence, in the performance of tasks with the IGT paradigm [22] [23] [25] [26]. On the contrary, the results of this study showed that younger individuals (7 - 11 years old) presented the most advantageous performance of the three groups, followed by the 12 - 14 years old group; and finally, with the lowest performance exhibited, by older teens (15 - 17 years).

These findings are consistent with the studies by Smith et al. [24], regarding the development trajectory of the decision-making process in the form of a J, which means that younger participants ( 8 - 11 years old) have a better performance than early adolescents (12 - 14 years old). However, a gradual improvement in performance was not found from this age (contrary to the assertions made by these authors), possibly due to a greater tendency in older adolescents (15 to 17 years old), to take risks and get away from the norm. It is noteworthy though, that the latter age group did not have a representative sample size to support these claims.

The performance showed by the group of 12 - 14 years old could be explained by the over-activation of limbic and subcortical structures such as the amygdala, hippocampus, caudate nucleus [15] and the nucleus accumbens [18] that occurs at the beginning of adolescence, and by hormonal factors of puberty in early adolescents [17], which would be more clearly demonstrated in tasks involving reinforcement such as the IGT. At the same time, it could be due to the relative immaturity of the prefrontal cortex, especially the ventromedial prefrontal cortex, whose development has proven to be much slower than some subcortical structures related to the reward system [14]. According to Oliva [12], these results may be due to the fact that at this age there is a greater imbalance between the cognitive and motivational circuits, which can lead to difficulties in imposing inhibitory control on impulsive behavior.

Younger children, meanwhile, who tended to give less disadvantageous responses than early adolescents, would present a generalized immaturity in all areas of the brain, making them less sensitive to reinforcement and therefore less likely to respond impulsively guided by the desire to obtain reward [24].

In the third group (15 - 17 years old), an upgrade in decision-making skills measured by the Hungry Donkey Task was not found, possibly because young people in middle and late adolescence, despite their advances in cognitive and executive functioning [27], tend to keep a preference for the search for new sensations and continue engaging in many risk behaviors, obviously affecting their decision-making process [28].

As for the learning process in the sample under study, an upward curve was found in the three groups. It is observed that subjects aged 7 - 11 years show a rising performance pattern relatively steady throughout the test, a result that coincides with that described by Crone and Van der Molen [23]. In the learning curve of the second group (12 - 14 years old), a marked increase was seen in the choice of advantageous options from the first to the second interval (trials 21 - 40); this same tendency is described by Crone et al. [20], who argue that children around the age of 14 are capable of producing rapid changes in their decision-making strategies.

Toward the last block of the test, in the same way as Crone and Van der Molen [23] have reported, the pattern of favorable and unfavorable responses tended to show a modest improvement, with a greater tendency toward choosing positive options. However, an increase was seen in the dispersion of data toward the final trials (higher standard deviation in R5) which could prove the existence of individual differences in the consolidation of learning, in the degree of effectiveness of decision-making processes, as well as in particular characteristics such as persistence and emotional and behavioral self-control.

In particular, the performance of the group aged 15 to 17 years presents a break halfway through the test, which may respond to a risk-taking behavior. Regarding this tendency, Hooper et al. [22] indicate that in this age group decision-making is not completely effective and even subjects aged just over 17 years fail to match the performance of adults, suggesting that the VMPFC and its connections continue maturing after this age.

The above has implications regarding the vulnerability of adolescents (15 - 17 years old) in risk-taking, since they require external control for their sensation-seeking tendencies [29]. Thus, real life for teens is strongly influenced by social determinants and feelings [17]. 
With regard to the preference of reward or punishment options, the greatest frequency of choice was found on P2. However, considering the upward learning curves for the three groups, it can be inferred that the choice of P2 was mostly present in the first test intervals, and that in the last trials the trend shifted towards a greater choice of P4.

It is observed that all groups showed high avoidance to P1, followed by P3, options having high frequency of punishment. It might be that, as predicted by prospect theory (Kahneman \& Tversky, 1979 cited by Bechara, 2007 [30]), at the beginning, children and adolescents are oriented towards finding reinforcement (P1), but quickly realize the high frequency and magnitude of loss brought about by this first option and therefore opt for P2, which provides the same amount of reinforcement than P1, but with a lower frequency of punishment. As explained by this theory, when it comes to a choice between a sure loss (P1) and a possible loss (P2), although the possible loss may be of great magnitude, neurologically intact subjects prefer the less probable loss (P2).

In connection therewith, Crone et al., and Kerr and Zelazo [19] state that children will tend to prefer options with infrequent punishment, compared to options with frequent punishment, suggesting that the choice will initially be determined by a low probability of punishment even if this is high in magnitude. The shift toward an option as P4, also with low frequency of punishment but with a lower amount of gain and loss than P2, can be explained not only by a learning process within the test, but by the development of the ability to change an association previously learned and to anticipate future consequences, particularly in children aged 12 years and older [26]. This corroborates what Matthias-Brand, Recknor, Grabenhorst and Bechara [31] have stated, in terms that on the IGT, the first trials are conducted under ambiguity, and the latter trials under risk.

In the case of the youngest (aged 7 - 11 years), performance is driven by a low frequency of punishment rather than their ability to anticipate future consequences or damages ("future myopia"). This ability, according to Crone et al. [20], develops with age, especially in conditions of occasional punishment where it is necessary to implement it in order to anticipate, whereas when punishment is frequent the likelihood of future losses seems obvious.

Therefore, changes in the development of decision-making are not associated with hypersensitivity to reinforcement or insensitivity to punishment, but rather with the fact that as children grow older, they seem to learn to anticipate future consequences based on their lived experiences. That is how, throughout childhood, the development of somatic markers is sensitive to the frequency with which punishments are experienced [20].

It should be noted that the fact that the younger children had achieved a better performance than the older ones, does not mean that the latter do not have the capacity to make decisions advantageously. It rather means that there are additional variables characteristic of the psychological and neuropsychological development of teenagers, such as the search for identity and independence by distancing themselves from the norm and seeking risks [32], as well as a slow development of the prefrontal cortex and the immaturity of frontostriatal circuits, which would determine a greater inhibition of such behaviors [16]. This could suggest that teenagers under 15 would benefit considerably from training in self-control and decision-making, which may mitigate the tendency to taking risks shown by adolescents aged 15 to 18 years.

Regarding response time, it was found that subjects who had a positive performance had invested a little more time in the development of the task than those who had a negative performance. It has been found that subjects who have a more disadvantageous performance on the test show faster responses to unfavorable options, compared with those who show a better performance. This may reflect a degree of impulsiveness in disadvantageous performers [24].

However, although it is expected that with age the response time will decrease according to a linear improvement in other cognitive processes such as processing speed and working memory [24], a relationship between performance in IGT (nonlinear development) and response time has not been found, nor was it observed in this study.

To conclude, it can be said that age differences observed in the performance on the Donkey Hungry Task and described by different authors about IGT, are consistent with the differences observed in real life in terms of decision-making, often preceded by affective and emotional factors (over cognitive ones). From the above, it follows that an improvement in the decision-making process would be supported by the maturity of affective aspects, rather than cognitive aspects [25]. Likewise, the role of a slow and progressive course in the development of cortical and subcortical structures and their connections during childhood and adolescence [33] is highlighted.

As a proposal for future research in this area, it could be suggested carrying out a study with subjects aged 17 - 19 years, since according to the theory is from 17 years of age onward when the most significant improve- 
ments in the process of decision-making can begin to be appreciated. Therefore, it is likely that a research conducted with a large and representative sample of subjects within this age range, does show an improved performance in late adolescence that the present study could not determine, bearing in mind that the sample of subjects aged 17 years was minimal (one participant). A longitudinal study that considers gender, cultural and demographic variables, as well as correlations with cold executive functions, would be perhaps the closest alternative to reach an understanding of an increasingly complex and particularly changing process such as decision-making.

Another proposal would be to assess clinical backgrounds in a more precise way, such as neurological and neuropsychological implications of perinatal hypoxia in decision-making since this condition is related to possible impairment in subcortical structures.

As for the test, it would be interesting to inquire whether changes occur in trends and scores observed in this study, by introducing a larger number of trials (200 for example). As it could be seen, towards the end of the 100 trials, an improvement in performance of almost all subjects was evident leading to hypothesize that by including more trials the average scores would be more positive and beneficial.

Finally, it can be said that this study did constitute a contribution to the challenge of Neuropsychology in Colombia, by collaborating in the generation of information to enable obtaining the validity and reliability of neuropsychological instruments for this population. As limitations only one subject was assessed 17 years, so it can not be concluded towards the older age range, also it could have been considered a sample of subjects from 17 to 19 years to see the performance at the end of the test adolescence.

\section{References}

[1] Verdejo-García, A., Benbrook, A., Funderburk, F., David, P., Cadet, J. and Bolla, K. (2007) The Differential Relationship between Cocaine Use and Marijuana Use on Decision-Making Performance over Repeat Testing with the Iowa Gambling Task. Drug and Alcohol Dependence, 90, 2-11. http://dx.doi.org/10.1016/j.drugalcdep.2007.02.004

[2] Damasio, A. (1994) Descartes’ Error: Emotions, Reason, and the Human Brain. Avon Books, New York.

[3] Bechara, A., Damasio, H. and Damasio, A. (2000) Emotion, Decision Making and the Orbitofrontal Cortex. Cerebral Cortex, 10, 295-307. http://dx.doi.org/10.1093/cercor/10.3.295

[4] García, M. (2012) Las funciones ejecutivas cálidas y el Rendimiento académico. Tesis Doctoral Universidad Complutense de Madrid.

[5] Contreras, D., Catena, A., Cándido, A., Perales, J. and Maldonado, A. (2007) Funciones de la Corteza Prefrontal Ventromedial en la Toma de Decisiones Emocionales. International Journal of Clinical and Health Psychology, 8, 285-313.

[6] Gordillo, F., Arana, J., Salvador, J. and Mestas, L. (2011) Emoción y Toma de Decisiones: Teoría y Aplicación de la Iowa GamblingTask. Revista Electrónica de Psicología Iztacala, 14, 333-353.

[7] Levav, M. (2005) Neuropsicología de la emoción. Particularidades en la infancia. Revista Argentina de Neuropsicología, 5, 15-24.

[8] Verdejo, A. and García, M. (2006) Funciones Ejecutivas y Toma de Decisiones en Drogodependientes: Rendimiento Neuropsicológico y Funcionamiento Cerebral. Editorial de la Universidad de Granada.

[9] Martínez-Selva, J., Sánchez, J. Bechara, A. and Román, F. (2006) Mecanismos cerebrales de la toma de decisiones. Revista de Neurología, 42, 411-418.

[10] Acuña, I. Castillo, D. Bechara, A. and Godoy, J. (2013) Toma de decisiones en adolescentes: Rendimiento bajo diferentes condiciones de información e intoxicación alcohólica. International Journal of Psychology and Psychological Therapy, 13, 195-214.

[11] Daza, M. and Arcas, P. (2002) Una apuesta teórica: Damasio y El error de Descartes.

[12] Oliva, A. (2007) Desarrollo cerebral y asunción de riesgos durante la adolescencia. Apuntes de Psicología, 25, $239-254$. http://www.apuntesdepsicologia.es/index.php/revista/article/view/77/79

[13] Spear, L. (2007) The Developing Brain and Adolescent-Typical Behavior Patterns: An Evolutionary Approach. In: Walker, E., Bossert, J. and Romer, D., Eds., Adolescent Psychopathology and the Developing Brain: Integrating Brain and Prevention Science, Oxford University Press, Oxford, 11-32.

[14] Ernst, M. and Spear, L. (2009) Reward Systems. In: de Haan, M. and Gunnar, M.R., Eds., Handbook of Developmental Social Neuroscience, Guilford Press, New York, 324-341.

[15] Goldberg, E. (2001) The Executive Brain: Frontal Lobes and the Civilized Mind. Oxford University Press, New York. 
[16] Moreno, A. (2012) Alteraciones Neuroanatómicas en los núcleos caudado y accumbens como marcador neurobiológico de mala respuesta al metilfenidato en el TDAH Infantil. Tesis Doctoral, Universidad Autónoma de Barcelona, Bellaterra.

[17] Steinberg, L. (2005) Cognitive and Affective Development in Adolescence. Trends in Cognitive Sciences, 9, 69-74. http://dx.doi.org/10.1016/j.tics.2004.12.005

[18] Verdejo, A., Orozco, C., Meersmans, M., Aguilar, F. and Pérez, M. (2004) Impacto de la gravedad del consumo de drogas sobre distintos componentes de la función ejecutiva. Revista de Neurología, 38, 1109-1116.

[19] Kerr, A. and Zelazo, P. (2004) Development of “Hot” Executive Function: The Children’s Gambling Task. Brain \& Cognition, 55, 148-157. http://dx.doi.org/10.1016/S0278-2626(03)00275-6

[20] Crone, E., Bunge, S., Latenstein, H. and Van der Molen, M. (2005) Characterization of Children’s Decision Making Sensitivity to Punishment Frequency, Not Task Complexity. Child Neuropsychology, 11, 245-263. http://dx.doi.org/10.1080/092970490911261

[21] Crone, E., Vendel, I. and Van der Molen, M. (2003) Decision-Making in Disinhibited Adolescents and Adults: Insensitivity to Future Consequences or Driven by Immediate Reward? Personality and Individual Differences, 35, 1625-1641. http://dx.doi.org/10.1016/S0191-8869(02)00386-0

[22] Hooper, C., Conklin, M. and Yarger, R. (2004) Adolescents’ Performance on the Iowa Gambling Task: Implications for the Development of Decision Making and Ventromedial Prefrontal Cortex. Developmental Psychology, 40, 11481158. http://dx.doi.org/10.1037/0012-1649.40.6.1148

[23] Crone, E. and Van der Molen, M. (2004) Developmental Changes in Real Life Decision Making: Performance on a Gambling Task Previously Shown to Depend on the Ventromedial Prefrontal Cortex. Developmental Neuropsychology, 25, 251-279. http://dx.doi.org/10.1207/s15326942dn2503 2

[24] Smith, D., Xiao, L. and Bechara, A. (2012) Decision Making in Children and Adolescents: Impaired Iowa Gambling Task Performance in Early Adolescence. Developmental Psychology, 48, 1180-1187. http://dx.doi.org/10.1037/a0026342

[25] Cauffman, E., Shulman, E., Steinberg, L., Claus, E., Banich, M. and Graham, S. (2010) Age Differences in Affective Decision Making as Indexed by Performance on the Iowa Gambling Task. Developmental Psychology, 46, 193-207. http://dx.doi.org/10.1037/a0016128

[26] Overman, W., Frassrand, K., Ansel, S., Trawalter, S., Bies, B. and Redmond, A. (2004) Performance on the IOWA Card Task by Adolescents and Adults. Neuropsychologia, 42, 1838-1851. http://dx.doi.org/10.1016/j.neuropsychologia.2004.03.014

[27] Best, J., Miller, P. and Jones, L. (2009) Executive Functions after Age 5: Changes and Correlates. Developmental Review, 29, 180-200. http://dx.doi.org/10.1016/j.dr.2009.05.002

[28] Reyna, V. and Farley, F. (2006) Risk and Rationality in Adolescent Decisión Making: Implications for Theory Practice, and Public Policy. Psychological Science in the Public Interest, 7, 1-44. http://dx.doi.org/10.1111/j.1529-1006.2006.00026.x

[29] Galvan, A., Hare, T., Parra, C., Penn, J., Voss, K. and Glover, G. (2006) Earlier Development of the Accumbens Relative to Orbitofrontal Cortex Might Underlie Risk-Taking Behavior in Adolescents. Journal of Neuroscience, 26, 68856892. http://dx.doi.org/10.1523/JNEUROSCI.1062-06.2006

[30] Bechara, A. (2007) Iowa Gambling Task Professional Manual. Psychological Assessment Resources, Lutz.

[31] Matthias-Brand, E., Recknor, F., Grabenhorst, A. and Bechara, A. (2007) Decisions under Ambiguity and Decisions under Risk: Correlations with Executive Functions and Comparisons of Two Different Gambling Tasks with Implicit and Explicit Rules. Journal of Clinical and Experimental Neuropsychology, 29, 86-99. http://dx.doi.org/10.1080/13803390500507196

[32] Oliva, A. and Antolin, L. (2010) Cambios en el cerebro adolescente y conductas agresivas y de asunción de riesgos. Estudios de Psicología, 31, 53-66. http://dx.doi.org/10.1174/021093910790744563

[33] Welsh, M. (2002) Developmental and Clinical Variations in Executive Functions. In: Molfese, D.L. and Molfese, V.J., Eds., Developmental Variations in Learning: Applications to Social, Executive Function, Language, and Reading Skills, Erlbaum, Mahwah, 139-185. 